\title{
Prevenção e controle de injúrias físicas: saímos ou não do século 20?
}

\author{
Injury prevention and control: will we or will we not step out of the twentieth century?
}

\author{
Danilo Blank*
}

$\mathbf{E}$ ma que se têm visto nestas páginas. Diferente das costumeiras descrições retrospectivas, baseadas em atendimentos hospitalares, o estudo sobre fatores de risco para injúrias em pré-escolares, de autoria de Sílvia Fonseca e colaboradores ${ }^{1}$, suscita várias reflexões que deveriam interessar a todo pediatra clínico que se preze.

Em primeiro lugar, cabe ressaltar a gritante desproporção entre a importância do tema - sob o prisma da morbimortalidade de crianças e jovens - e a exígua quantidade de estudos a ele relacionados. Seria oportuno que todos nós ponderássemos um pouco mais, por exemplo, sobre dois documentos relevantes e minuciosos, divulgados recentemente, em que a OMS e o UNICEF reiteram o que muita gente parece não querer enxergar: as injúrias físicas constituem um enorme problema de saúde pública entre crianças e jovens $^{2,3}$. A Tabela 1, adaptada dos dados da OMS, fala por si: as causas externas respondem por $53 \%$ da sobrecarga total das dez principais doenças, entre 5 e 14 anos, nos países menos ricos das Américas. Mesmo incluindo os primeiros anos de vida, com todas as suas peculiaridades, o peso das injúrias físicas é notório. O relatório do UNICEF, que se detém na mortalidade, enfatiza que $98 \%$ das mortes de crianças e jovens causadas por injúrias físicas ocorrem nos países em desenvolvimento, apontando como os principais fatores de risco a pobreza, mãe solteira e jovem, baixo nível de educação materna, habitações pobres, famílias numerosas e uso de álcool e drogas pelos pais $^{2}$. E mais, segundo o relatório "The Global Burden of Disease" (um marco na caracterização da injúria física como problema prioritário de saúde pública), no âmbito mundial, as causas externas representam $15 \%$ da sobrecarga de mortes e incapacitação, penalizando os países do Terceiro Mundo em escala quase duplicada; para os próxi-

\footnotetext{
* Membro do Departamento Científico de Segurança da Criança e do Adolescente da Sociedade Brasileira de Pediatria. Professor Adjunto do Departamento de Pediatria da Faculdade de Medicina da Universidade Federal do Rio Grande do Sul.
}

mos vinte anos, o relatório projeta um aumento desse índice para cerca de $20 \%{ }^{4}$. Ou seja, trata-se de uma questão muito nossa, que, apesar dos maus prognósticos, seguimos menosprezando.

A moderna ciência do controle de injúrias físicas - a tentativa de diminuir as conseqüências do trauma por meio da prevenção primária, primeiros-socorros mais efetivos e técnicas melhores de reabilitação - consolidou-se, na segunda metade do século passado, como uma das bases da pediatria clínica ${ }^{5,6}$. A epidemiologia, a biomecânica e a ciência do comportamento constituem seus três pilares fundamentais. Neste contexto, o trabalho de Fonseca e colaboradores pode ser considerado um marco, pois é o primeiro estudo prospectivo de base populacional, com o objetivo de avaliar os fatores de risco associados a injúrias não intencionais, de que se tem notícia na literatura pediátrica brasileira. Traz um enfoque que sinaliza de modo positivo o alinhamento da investigação clínica nacional com as tendências acadêmicas globais. Caso sua inspiração motive pesquisas semelhantes em outros lugares, conforme expressam os autores, estaremos pisando no século 21, pelo menos no âmbito da ciência do controle das injúrias físicas. Será que isto se confirma?

Alguns dos resultados do artigo em questão, entretanto, merecem ser avaliados com cautela, por conta de vieses de perspectiva. Para o pediatra que tenta entender os fatores determinantes das injúrias físicas, a fim de tentar agir preventivamente, primeiro interessa saber quando, como e quem está sujeito a que tipos específicos de risco. Em seguida, lhe interessa saber o que funciona efetivamente como fator protetor. Dados bem fundamentados de literatura nos mostram que os principais fatores de risco para injúrias físicas dependem da idade, do sexo, da pobreza e da urbanização ${ }^{3,6-9}$. De um modo geral, lactentes e pré-escolares sofrem mais queimaduras, afogamentos, quedas e intoxicações; escolares sofrem mais atropelamentos e quedas de bicicletas; adolescentes estão mais sujeitos a afogamentos, traumas no trânsito e por armas de fogo. A questão da idade é crucial: mesmo que o pediatra não seja capaz de modificar a idade de seus pacientes, pode sempre tentar, por 
Tabela 1 - Principais causas de sobrecarga de doenças*, países americanos de baixa e média renda, ambos os sexos, DALYs ${ }^{\dagger}$ perdidos, 1998

\begin{tabular}{|c|c|c|}
\hline Ordem & 0-4 anos & 5-14 anos \\
\hline 1 & $\begin{array}{c}\text { Doenças perinatais } \\
5.061 .346\end{array}$ & $\begin{array}{l}\text { Trânsito } \\
1.055 .375\end{array}$ \\
\hline 2 & $\begin{array}{c}\text { Diarréia } \\
3.142 .287\end{array}$ & $\begin{array}{l}\text { Quedas } \\
636.933\end{array}$ \\
\hline 3 & $\begin{array}{c}\text { Infecções respiratórias baixas } \\
2.441 .582\end{array}$ & $\begin{array}{l}\text { Cárie dentária } \\
481.892\end{array}$ \\
\hline 4 & $\begin{array}{c}\text { Anomalias congênitas } \\
2.076 .326\end{array}$ & $\begin{array}{c}\text { Parasitoses intestinais } \\
387.886\end{array}$ \\
\hline 5 & $\begin{array}{c}\text { Desnutrição protéico-energética } \\
977.479\end{array}$ & $\begin{array}{l}\text { Diarréia } \\
294.979\end{array}$ \\
\hline 6 & $\begin{array}{c}\text { Pertussis } \\
593.042\end{array}$ & $\begin{array}{c}\text { Asma } \\
279.548\end{array}$ \\
\hline 7 & $\begin{array}{c}\text { Distúrbios endócrinos } \\
511.677\end{array}$ & $\begin{array}{l}\text { Afogamento } \\
268.619\end{array}$ \\
\hline 8 & $\begin{array}{c}\text { Tétano } \\
434.039\end{array}$ & $\begin{array}{c}\text { Infecções respiratórias baixas } \\
259.647\end{array}$ \\
\hline 9 & $\begin{array}{l}\text { DST, excluindo HIV } \\
265.486\end{array}$ & $\begin{array}{l}\text { Anemias } \\
232.585\end{array}$ \\
\hline 10 & $\begin{array}{r}\text { Quedas } \\
259.157\end{array}$ & $\begin{array}{l}\text { Violência } \\
213.143\end{array}$ \\
\hline 11 & $\begin{array}{l}\text { Anemias } \\
245.278\end{array}$ & $\begin{array}{c}\text { Epilepsia } \\
188.340\end{array}$ \\
\hline 12 & $\begin{array}{l}\text { Meningite } \\
214.985\end{array}$ & $\begin{array}{c}\text { Distúrbios endócrinos } \\
141.927\end{array}$ \\
\hline 13 & $\begin{array}{l}\text { Trânsito } \\
214.141\end{array}$ & $\begin{array}{c}\text { Leucemia } \\
130.583\end{array}$ \\
\hline 14 & $\begin{array}{c}\text { HIV } \\
192.245\end{array}$ & $\begin{array}{c}\text { Transt. obsessivo-compulsivo } \\
124.755\end{array}$ \\
\hline 15 & $\begin{array}{c}\text { Afogamento } \\
139.149\end{array}$ & $\begin{array}{c}\text { Anomalias congênitas } \\
119.962\end{array}$ \\
\hline
\end{tabular}

meio da orientação, minimizar o desacerto entre riscos específicos e fatores de resiliência. E há evidências de que isto funciona: a educação para a segurança é factível, tanto no âmbito individual quanto no comunitário ${ }^{10,11}$. Fonseca e colaboradores optaram por avaliar uma subamostra de sua coorte, durante um período muito restrito de seu desenvolvimento, justamente a faixa pré-escolar, na qual a incidência de injúrias físicas costuma ser particularmente baixa. Assim, embora tenham feito uma bela demonstração da eficácia do instrumento de avaliação testado (o diário de “acidentes"), ficou o estudo, por ora, privado de ver os riscos sob a ótica dos estágios do desenvolvimento. Fica a idéia para estudos posteriores.

Além disso, o artigo - ou, pelo menos, o segmento do estudo que os autores revelam neste momento - não dá informações detalhadas sobre as diferentes gravidades de lesões, o que é muito importante para a definição de medidas de controle. Cerca de metade das crianças da amostra avaliada sofreram pelo menos uma injúria física no período de um mês, o que constitui uma incidência alta. Sem dúvida, na maioria destes casos tratava-se de quedas e lacerações de gravidade leve, cuja prevenção tem importância menor. O delineamento mais apropriado para estudar os fatores de risco para injúrias mais graves, muito menos frequientes, seria o de casos e controles ${ }^{6}$. Mas isto também é idéia para outros trabalhos.

O fato de não terem sido encontradas associações significativas de injúrias com a renda familiar ou com a escolaridade dos pais, na contramão do consenso geral visto na literatura, mereceria uma discussão mais aprofundada. De acordo com o relatório do UNICEF, já citado, para cada 100.000 crianças nascidas nas 26 nações mais desenvolvidas do mundo, menos de 200 morrem por trauma até os 15 anos; no mundo em desenvolvimento, esta cifra sobe para 
mais de $1.000^{3}$. Um possível viés poderia advir da baixa incidência de casos graves na amostra estudada, o que não temos condições de avaliar apenas com os dados apresentados. Outra explicação poderia ser uma menor variabilidade socioeconômica dentro da população estudada. Embora saibamos que no município de Pelotas há muitas famílias bem pobres e que a seleção sistemática da amostra foi feita dentro de critérios inquestionáveis, talvez os resultados fossem outros se tivessem sido analisados casos com uma amplitude maior de diferenças sociais, segundo sugerem alguns autores ${ }^{12}$.

Por outro lado, o desfecho usado no estudo de Fonseca e colaboradores - o número de "acidentes" em que a criança sofreu injúria física - é muito amplo, limitando a aplicabilidade dos seus achados. A injúria física pode ser encarada como uma doença, mas ela é multifacetada; toda intervenção preventiva tem que ser necessariamente apontada a um alvo específico. De nada adianta querer prevenir afogamentos com o uso do cinto de segurança; assim como não se previnem queimaduras com capacetes para ciclistas; ou intoxicações com cercas ao redor de piscinas. Orientações muito abertas, do tipo "proteja seu filho", ainda mais quando espargidas em campanhas desenfocadas, costumam simplesmente deixar os pais angustiados, tendo muito pouca efetividade na prevenção de injúrias. É essencial que se avance mais, determinando quais são os riscos específicos para tipos determinados de injúrias físicas, para, a seguir, definir estratégias preventivas com foco dirigido que se provem efetivas, na prática-e, por fim, estabelecer prioridades e implementá-las. De novo, bastante trabalho para estudos futuros.

A propósito, hoje em dia o pediatra encontra na literatura quantidades crescentes de evidências confiáveis sobre o que funciona no controle das injúrias físicas. Uma cuidadosa revisão sistemática, recentemente publicada ${ }^{13,14}$, chegou às seguintes conclusões: esquemas de acalmação de tráfego urbano reduzem o número de injúrias a pedestres e ciclistas; o treinamento intensivo de escolares melhora seu comportamento como pedestres; campanhas multisetoriais promovem o aumento do uso de capacetes por ciclistas; legislação obrigando o uso de assentos de segurança infantis leva à redução da incidência de traumatismos em crianças ocupantes de veículos automotores; campanhas de promoção do uso de alarmes de fumaça podem aumentar efetivamente o seu uso; legislação sobre tampas de segurança em medicamentos diminui a incidência de intoxicações; intervenções baseadas na comunidade podem melhorar o nível geral de segurança, embora a qualidade da evidência seja limitada; campanhas públicas informativas aumentam o conhecimento sobre segurança e riscos, mas continua não havendo evidências de que reduzam a incidência de injúrias.

Como se vê, para um problema de tamanha complexidade - cujas múltiplas soluções dificilmente trarão impactos muito marcantes - o conhecimento tem aumentado bastante. Mas precisa aumentar muito mais. Também é evidente que muito pouco pode ser feito pelo pediatra sozinho, no seu contexto de ação clínica ${ }^{15}$, embora, como já foi dito, haja evidências de que algum impacto positivo possa ser alcançado por meio da educação para a segurança no âmbito individual ou comunitário, se o pediatra estiver realmente convencido de que isto é importante. Para tanto, é fundamental que mais trabalhos com a qualidade científica deste aqui comentado cheguem ao Jornal de Pediatria. Aí sim, poderemos dizer que, no que tange ao controle de injúrias físicas, deixamos para trás o século 20 .

\section{Referências bibliográficas}

1. Fonseca SR, Victora CG, Halpern R, Barros AJD, Lima RC, Monteiro LA, et al. Fatores de risco para injúrias acidentais em pré-escolares. J Pediatr (Rio J) 2002;78:97-104.

2. Krug E, ed. Injury: a leading cause of the global burden of disease. Geneva: World Health Organization; 1999. Disponível: www.who.int/violence_injury_prevention/pdf/injuryburden.pdf. Acessado: 21/03/2002.

3. UNICEF. A league table of child deaths by injury in rich nations. Innocenti Report Card No 2. Florence: UNICEF Innocenti Research Centre; 2001. Disponível: www.unicef-icdc.org. Acessado: 21/03/2002.

4. Murray CJL, Lopez AD. Mortality by cause for eight regions of the world: Global Burden of Disease Study. Lancet 1997;349:1269-76.

5. Rivara FP. Pediatric injury control in 1999: Where do we go from here? Pediatrics 1999:103:883-8.

6. Committee on Injury and Poison Prevention, American Academy of Pediatrics. Injury Prevention and Control for Children and Youth. 3rd ed. Elk Grove Village, IL: AAP; 1997.

7. Rivara FP, Aitken M. Prevention of injuries to children and adolescents. Adv Pediatr 1998;45:37-72.

8. National Center for Injury Prevention and Control. Injury Fact Book 2001-2002. Atlanta, GA: Centers for Disease Control and Prevention; 2001.

9. Stark AD, Bennet GC, Stone DH, Chishti P. Association between childhood fractures and poverty: population based study. BMJ 2002;324:457.

10. DiGuiseppi C, Roberts IG. Individual-level injury prevention strategies in the clinical setting. Future Child 2000;10:53-82.

11. Klassen TP, MacKay JM, Moher D, Walker A, Jones AL. Community-based injury prevention interventions. Future Child 2000;10:83-110.

12. Lu TH. International comparisons: they do help and are essential for avoiding type III error. Inj Prev 2001;7:270-1.

13. Towner E, Dowswell T, Jarvis S. Updating the evidence. A systematic review of what works in preventing childhood unintentional injuries: Part 1. Inj Prev 2001;7:161-4.

14. Towner E, Dowswell T, Jarvis S. Updating the evidence. A systematic review of what works in preventing childhood unintentional injuries: Part 2. Inj Prev 2001;7:249-53.

15. Pless B. The non-existent role of injury prevention in medical practice. Lancet 2000;355:1807. 